\title{
Conflito trabalho-família: Um estudo com motoristas profissionais
}

\author{
Work-Family Conflict: A study of professional drivers \\ Conflicto trabajo-familia: Un estudio con conductores profesionales
}

\author{
Ana Raquel SILVA ${ }^{1}$ \\ Isabel Soares SILVA \\ Universidade do Minho, Braga, Portugal
}

Resumo

Este estudo pretende contribuir para a compreensão do conflito entre trabalho e família em motoristas profissionais que trabalham com transporte de passageiros e da influência que outras variáveis possam ter nesse âmbito. Foi analisada especificamente a relação entre o conflito trabalho-família e as variáveis sociodemográficas (idade), do contexto familiar (número e idade dos filhos) e do contexto profissional (duração da jornada de trabalho, satisfação com o trabalho, suporte social dos supervisores e suporte social dos colegas de trabalho). Os dados foram recolhidos por meio de questionário, tendo participado 154 trabalhadores de uma empresa de transportes de passageiros do norte de Portugal. Todos os participantes eram do sexo masculino, e a maioria deles tinha idade entre 40 e 59 anos, eram casados e tinham filhos. Os resultados revelaram que os motoristas apresentam valores médios relativamente reduzidos de conflito trabalho-família e indicaram que a idade dos filhos, o número de horas trabalhadas semanalmente e a percepção de suporte dos supervisores constituíram preditores significativos do conflito trabalho-família.

Palavras-chave:

Conflito trabalho-família; suporte social dos supervisores; suporte social dos colegas; motoristas profissionais.

Abstract This study aims to contribute to the understanding of work-family conflict among professional drivers, and the influence that other variables may have in that context. We analyzed the relationship between work-family conflict and socio-demographic variables (age), family context (number of children and their ages), and professional context (number of working hours, job satisfaction, and perception of supervisor and co-worker social support) in particular. Data were collected through a questionnaire administered to 154 male workers of a passenger transport company in the north of Portugal. The majority of the participants were aged 40-50, were married, and had children. Data showed that the drivers reported relatively low mean levels of workfamily conflict. Results also showed that the age of their children, weekly hours worked, and the perception of supervisor support were significant predictors of work-family conflict.

Keywords:

Work-family conflict; social support from supervisors; social support from co-workers; professional drivers.

\section{Resumen}

Este estudio pretende contribuir a la comprensión del conflicto entre trabajo y familia en conductores profesionales que trabajan con el transporte de pasajeros, y de la influencia que otras variables puedan tener en ese contexto. Específicamente, se analizó la relación entre el conflicto trabajo-familia y las variables sociodemográficas (edad), el contexto familiar (número de hijos y su edad), así como el contexto profesional (duración de la jornada de trabajo, satisfacción laboral, apoyo social de los supervisores y soporte social de los compañeros de trabajo). Los datos se recogieron mediante un cuestionario aplicado a 154 trabajadores hombres de una empresa de transporte de pasajeros del norte de Portugal. La mayoría de los participantes tenía entre 40 y 59 años, estaban casados y tenían hijos. Los resultados muestran que los conductores tienen valores medios relativamente bajos de conflicto trabajo-familia. Los resultados también indicaron que la edad de los hijos, el número de horas

\footnotetext{
1 Endereço para correspondência: Escola de Psicologia da Universidade do Minho, Campus de Gualtar, Braga, Portugal 4710057. Email: anarsilva11@gmail.com; isilva@psi.uminho.pt

As autoras gostariam de manifestar o seu agradecimento à organização que possibilitou a realização do estudo, bem como a todos os motoristas que dele participaram.
} 
trabajadas semanalmente y la percepción de apoyo de los supervisores constituyeron predictores significativos del conflicto trabajo-familia.

Palabras-clave:

Conflicto trabajo-familia; apoyo social de los supervisores; apoyo social de los compañeros de trabajo; conductores profesionales.

A s últimas décadas foram marcadas por mudanças significativas no seio das famílias e na composição da força de trabalho, de que são exemplo o aumento de mulheres no mercado de trabalho, o crescente número de casais de dupla carreira, de famílias monoparentais (Bianchi \& Milkie, 2010), e, ainda, de famílias com responsabilidade pelo cuidado de pessoas idosas dependentes (Netemeyer, McMurrian, \& Boles, 1996). Os dados apresentados por Guerreiro, Lourenço e Pereira (2006), por exemplo, revelam que nas últimas três décadas anteriores a 2000, em Portugal, a percentagem de mulheres no mercado de trabalho aumentou de modo significativo, tendo atingido os $60 \%$ nesse período. Nesse mesmo ano, segundo a mesma fonte, os casais de dupla carreira que trabalhavam o tempo inteiro e tinham crianças era de $67 \%$. No contexto dessas mudanças, inúmeros estudos têm explorado a temática da interação trabalho-família, conceito emergente de investigação nas décadas de 1960 e 1970. Entender essa interação tornou-se importante para a compreensão das famílias, das organizações e da sociedade como um todo (Edwards \& Rothbard, 2000).

No que diz respeito às organizações atuais, como sublinham Chambel e Ribeiro (2014), a interface trabalhofamília reveste-se de uma grande importância por, entre outras razões, o equilíbrio entre esses dois universos influenciar os níveis de bem-estar, as atitudes e os comportamentos dos trabalhadores. Por outro lado, as próprias organizações podem desenvolver esforços no sentido de promover ou apoiar tal equilíbrio por meio da implementação dos designados programas "amigos da família" (family-friendly programs) (Sutton \& Noe, 2005). Globalmente, tais iniciativas formais procuram: (a) substituir o trabalhador no cuidado de seus familiares, como é o caso, por exemplo, da oferta de serviço de creches; ou (b) proporcionar ao trabalhador maior flexibilidade na gestão de sua jornada de trabalho, sobretudo do ponto de vista temporal, como é o caso da disponibilização de horários de trabalho flexíveis. Em ambas as iniciativas, é esperado que sua implementação ajude a evitar, ou a minimizar, o conflito trabalho-família dos trabalhadores.

Este estudo se propõe a estudar o conflito trabalho-família em motoristas profissionais de transporte de passageiros (todos do sexo masculino) e sua relação com variáveis sociodemográficas (idade), familiares (número e idade dos filhos) e do contexto organizacional (duração da jornada de trabalho semanal, suporte do supervisor e dos colegas de trabalho e satisfação com o trabalho).

A temática do conflito entre a vida profissional e familiar tem aparecido em maior número em estudos com populações do sexo feminino (p. ex., Khan, 2014; Sultana, 2013). Como referem esses autores, mesmo com as mudanças de paradigma na cultura atual, predomina a ideia de que o conflito entre as exigências do trabalho e da família pertence em maior escala às mulheres. Em todo o caso, e ainda que de forma bem menos expressiva, têm sido realizados alguns estudos (Coltrane, Miller, DeHaan, \& Stewart, 2013; Pinto, 2012; Vandello, 2013; Williams, 2010) sobre como os homens experienciam esse conflito. A crescente constatação de que os homens também experienciam conflito entre as responsabilidades do trabalho e da família (Coltrane et al., 2013; Vandello, 2013) suscitou interesse para a realização deste estudo com uma amostra composta somente por indivíduos do sexo masculino, sendo todos motoristas profissionais de transporte de passageiros.

Estudar a temática do conflito trabalho-família em motoristas profissionais suscita interesse, pois, como referem Tüchsen, Hannerz, Roepstornff e Krause (2006), trata-se de uma profissão estressante por natureza. O estudo de Silveira, Abreu e Santos (2014), por exemplo, com base em 50 entrevistas com motoristas em uma empresa de ônibus urbano de uma cidade brasileira, constatou que $98 \%$ dos profissionais consideravam que o trânsito interferia negativamente no desenvolvimento de sua atividade profissional; $36 \%$, por sua vez, também consideravam negativa a interferência dos passageiros. Além disso, $72 \%$ dos profissionais consideravam que seu posto de trabalho era inadequado devido à presença de ruído e de calor e às condições de assento. $\mathrm{O}$ estudo de Battiston, Cruz e Hoffmann (2006), também com motoristas de transporte coletivo urbano de uma cidade brasileira, verificou que os engarrafamentos e os outros veículos da via foram os aspectos que mais contribuíam para a irritação dos profissionais. Foi verificado também que cerca de $40 \%$ dos motoristas referiram usar medicação regularmente para dores de cabeça, nos membros superiores ou inferiores, no pescoço ou na musculatura como um todo. 
No contexto desses resultados, assinala-se ainda que esses profissionais desenvolvem sua atividade sentados na maior parte da jornada de trabalho e têm necessidade de fazer movimentos repetitivos dos membros superiores. Em suma, eles ficam sentados durante praticamente toda a jornada de trabalho e encontram-se expostos diariamente a ambientes que não podem controlar (em especial, tráfego rodoviário e contato com os passageiros) que podem ser geradores de estresse significativo, e também a horários irregulares e muitas vezes realizados em períodos valorizados pela família e pela sociedade (p. ex., final de semana), o que pode contribuir para uma deterioração da vida social e, principalmente, familiar (De Vitta et al., 2013; Tüchsen et al., 2006). Não obstante a potencial relevância da temática nesse grupo ocupacional, esta tem sido escassamente estudada, em contraste com temáticas relacionadas à saúde e/ou à segurança rodoviária.

\section{Conflito trabalho-familia}

Goldani (2002) atribui o crescente interesse pela temática da relação trabalho-família às constantes mudanças que têm surgido nas famílias tradicionais. Como refere o autor, com a industrialização, muitos casais sentiram necessidade de mudar o paradigma do homem como "chefe de família" e da mulher como "fada do lar", dado que, com o aumento da concorrência no mercado de trabalho, a deterioração salarial e o aumento do custo de vida fez aumentar o número de famílias nas quais os dois cônjuges compõem a força de trabalho. Com tais mudanças de padrão nas famílias atuais, os indivíduos podem se deparar com um conflito entre as responsabilidades laborais e as familiares, dificultando a organização do tempo na conciliação desses dois domínios da vida. Atualmente, são mais evidentes os casais que, além de desempenharem o papel de pai/mãe, marido/mulher, trabalhador/trabalhadora, são, ainda, requisitados a executar trabalho doméstico (Akintayo, 2010). Os indivíduos incapazes de equilibrar essas componentes de sua vida deparam-se com um conflito entre a vida no trabalho e a familiar. Greenhaus e Beutell (1985) definem conflito trabalho-família como "uma forma de conflito inter papéis no qual as pressões dos papéis provenientes dos domínios profissionais e familiares são mutuamente incompatíveis em algum aspecto” (p. 77), representando tal definição, porventura, uma das mais citadas na literatura.

Esses autores, partindo da revisão da literatura acerca do conflito entre os papéis profissionais e familiares, propõem como fontes de origem do conflito trabalho-família os seguintes fatores: (a) o tempo dedicado às exigências de um papel torna difícil responder às exigências do outro (conflito baseado no tempo; p. ex., excessiva carga horária de trabalho); (b) a(s) pressão(ões) decorrente(s) da participação em um papel torna(m) difícil a resposta às exigências do outro (conflito baseado na tensão; p. ex., quando a fadiga ou irritabilidade decorrente da realização de um papel compromete a performance na realização do outro papel); e (c) determinados padrões comportamentais na realização de um papel podem ser incompatíveis com as expectativas face à conduta associada à realização do outro papel (conflito baseado no comportamento, p. ex., os estereótipos/crenças de agressividade associados aos contextos de trabalho podem não ser compatíveis com as expectativas de condutas associadas ao ambiente familiar).

A literatura tem explorado os preditores do conflito trabalho-família. De acordo com a metanálise de Michel, Kotrba, Mitchelson, Clark e Baltes (2011), o conflito trabalho-família tem como antecedentes os estressores associados ao papel profissional, ao envolvimento no papel profissional, ao suporte social no trabalho, às características do trabalho e, ainda, à personalidade. Além da relação do suporte social dos supervisores e dos colegas de trabalho com o conflito trabalho-família, estudada neste trabalho e abordada mais adiante, fatores como o número de horas de trabalho, a idade dos indivíduos, o número de filhos e sua idade podem afetar igualmente esse tipo de conflito, como indicam diversos estudos (Brandão, 2011; DiRenzo, Greenhaus, \& Weer, 2011; Netemeyer et al., 1996; Pinto, 2012; Zhang \& Liu, 2011). Além dos preditores do conflito trabalho-família, diversos autores têm estudado também o impacto desse conflito, seja em termos individuais, como o nível do estresse e do bem-estar, seja em termos de variáveis organizacionais, como satisfação no trabalho ou compromisso organizacional (Chambel \& Ribeiro, 2014; Netemeyer et al., 1996; Oliveira, Cavazotte, \& Paciello 2013; Pinto, 2012; Rathi \& Barath, 2012).

$\mathrm{Na}$ investigação realizada por Netemeyer et al. (1996), com vista ao desenvolvimento e validação de uma medida de conflito trabalho-família baseada em três amostras (professores e administradores, proprietários de pequenos negócios/empresas e vendedores de imóveis), foi estudada a associação entre tal construto e diversas variáveis, entre elas o número de crianças a morar em casa, o número de horas de trabalho e a satisfação com o trabalho. Em relação ao número de crianças, foram observados resultados mistos, sendo que apenas na 
primeira amostra foi obtida uma correlação positiva e estatisticamente significativa com o conflito trabalhofamília. Contrariamente à situação anterior, foram observadas correlações estatisticamente significativas entre tal conflito e o número de horas trabalhadas bem como entre este e a satisfação profissional em todas as amostras e no sentido esperado, ou seja, positivo no primeiro caso, e negativo no segundo.

Brandão (2011), com base em uma amostra de 82 profissionais a desenvolver atividade no setor das tecnologias de informação, observou que nem o número de filhos nem a idade dos participantes encontravam-se correlacionados com o conflito trabalho-família. A ausência de associação entre o número de filhos e o conflito trabalho-família também foi verificada no estudo de Pinto (2012), com 139 motoristas profissionais portugueses (de longa distância e que fazem entregas). Nesse estudo, contrariamente ao anterior, foi observada uma associação negativa entre a idade dos motoristas e o conflito-trabalho família e também que os indivíduos com filhos mais novos eram os que tendiam a exibir maior conflito.

O estudo de Allen e Finkelstein (2014) com cerca de 700 casais de dupla carreira a tempo inteiro analisou a relação entre o conflito trabalho-família, a idade, o gênero e a fase do ciclo da vida familiar. O conjunto dos dados obtidos apontou para o fato da fase do ciclo familiar não ser apenas um substituto (proxy) da idade dos indivíduos, sendo que esta apresentava uma relação de natureza monotônica e não linear com o conflito trabalho-família. O nível de conflito trabalho-família mais elevado foi observado no período em que os casais tinham filhos com idades iguais ou inferiores a 5 anos, e o mais baixo, na fase correspondente ao "ninho vazio" (ou seja, indivíduos com mais de 54 anos e sem filhos morando em sua casa).

Em termos dos antecedentes do contexto organizacional, a literatura (p. ex., DiRenzo et al., 2011; Michel et al., 2011; Netemeyer et al., 1996; Zhang \& Liu, 2011) é consensual em associar maiores níveis de conflito trabalho-família a um maior número de horas de trabalho. Tais resultados enfatizam a fonte de conflito baseada no tempo proposta por Greenhaus e Beutell (1985), em que o tempo dedicado às exigências de um papel torna difícil responder às exigências de outro papel.

Como referido anteriormente, além do estudo dos antecedentes, outros estudos abordam as consequências do conflito trabalho-família para o trabalhador e/ou para a organização. Hill (2005) e Mesmer-Magnus e Viswesvaran (2009), em seus estudos, conceitualizam que conseguir equilíbrio entre trabalho e família gera elevados níveis de satisfação com a família, funcionamento familiar, bem-estar do indivíduo, satisfação com o trabalho e envolvimento com a organização. O estudo de Oliveira et al. (2013), com base em uma amostra de cerca de 300 trabalhadores com nível superior completo, observou um impacto significativo do conflito trabalho-família com a satisfação no trabalho. Além desse resultado, também foi observado impacto positivo significativo de tal conflito no estresse e na intenção de deixar a empresa. Considerando alguns dos estudos já citados anteriormente, foi observada relação negativa entre o conflito trabalho-família e compromisso organizacional (Brandão, 2011; Pinto, 2012), satisfação com a vida (Pinto, 2012) e satisfação com o trabalho (Netemeyer et al., 1996).

Partindo da revisão anterior sobre a relação entre as variáveis sociodemográficas, familiares e profissionais e o conflito trabalho-família, são apresentadas as seguintes hipóteses:

$\mathrm{H}_{1}$ : A idade dos motoristas relaciona-se negativamente com o conflito trabalho-família.

$\mathrm{H}_{2}$ : Os motoristas com filhos mais novos, em comparação com os que têm filhos mais velhos, apresentam, em média, maior conflito trabalho-família.

$\mathrm{H}_{3}$ : Os motoristas que trabalham mais de 40 horas semanais, em comparação com os que trabalham menos de 40 horas semanais, apresentam, em média, maior conflito trabalho-família.

$\mathrm{H}_{4}$ : O conflito trabalho-família dos motoristas relaciona-se negativamente com a satisfação com o trabalho.

\section{Conflito trabalho-família e suporte social do contexto laboral}

Nos últimos anos, as organizações têm mostrado maior sensibilidade para com os indivíduos que não conseguem equilibrar o trabalho e a família (Breaugh \& Frye, 2008; Mills, Matthews, Henning, \& Woo, 2014; Zhang \& Liu, 2011), sendo que, como referem McManus, Korabik, Rosin e Kelloway (2002), o suporte dos supervisores e dos colegas de trabalho pode auxiliar na redução do conflito entre essas duas esferas da vida dos trabalhadores.

Jacobs e Gerson (2004) consideram que a existência de percepção de apoio por parte dos supervisores no local de trabalho pode contribuir para um decréscimo das consequências do conflito e pode funcionar como impulsionador de integração dos papéis laborais e familiares. Sob esse ponto de vista, alguns estudos 
(Grzywacz \& Marks, 2000; Hill, 2005) evidenciaram que o apoio percebido por parte da supervisão está relacionado com uma menor percepção de conflito trabalho-família, menor estresse individual e maior satisfação com a vida e com o trabalho.

O estudo de Oliveira et al. (2013), a que já fizemos referência, avaliou o impacto de práticas informais no conflito trabalho-família, especificamente o suporte gerencial (entendido como o suporte recebido do supervisor imediato quando o trabalhador busca equilibrar responsabilidades no trabalho e na família) e a percepção de consequências na carreira (entendido como a percepção que o trabalhador tem acerca das consequências em suas perspectivas de carreira/promoção caso opte por um balanço mais equilibrado entre os universos profissional e familiar). Os resultados indicaram que o suporte gerencial estava inversamente relacionado com o conflito trabalho-família e com a percepção das consequências na carreira.

Além de reforçar a importância do suporte do supervisor na gestão da interface trabalho-família, o conjunto desses resultados reforça também a importância de uma cultura organizacional designada como "amiga da família" (family-friendly culture) (Thompson, Beauvais, \& Lyness, 1999), ou seja, de um ambiente no qual a gestão auxilie os trabalhadores que estão motivados para um melhor equilíbrio entre a vida laboral e a familiar, tendo diversos estudos empíricos suportado a sua relevância quando se procura compreender, por exemplo, a disponibilização de práticas formais amigas da família e seu impacto na redução do conflito trabalho-família (Allen, 2001; Breaugh \& Frye, 2008; Mills et al., 2014). Globalmente, tais estudos têm vindo chamar a atenção que a disponibilização de práticas formais (p. ex., horários flexíveis, part-time), pode não ser condição suficiente para a sua utilização por parte dos trabalhadores. Com efeito, a decisão dos trabalhadores de utilizar tais iniciativas formais vai ser influenciada pela percepção que estes possam ter do contexto organizacional face às questões familiares e às implicações daí decorrentes (p. ex., implicações em termos de perspectivas de carreira).

Em suma, o conjunto da evidência disponível tem chamado a atenção para o papel que o contexto organizacional pode desempenhar na gestão da interface trabalho-família, não só por meio de políticas e programas formais que pode disponibilizar, mas por meio do desenvolvimento de uma cultura organizacional sensível às exigências/responsabilidades familiares, traduzida no modo como os supervisores diretos fazem a gestão no cotidiano dessa interface junto à força de trabalho.

Além dos supervisores, mais recentemente, alguns autores (Breaugh \& Frye, 2008; Mesmer-Magnus, Murase, DeChurch, \& Jimenez, 2010; Michel et al., 2011; Rathi \& Barath, 2012) têm comprovado também a importância do papel do colega de trabalho como redutor do conflito trabalho-família. Segundo MesmerMagnus e Viswesvaran (2009), devido à importância dada hoje em dia pelas organizações ao trabalho em equipe, o colega de trabalho adquire um papel importante na redução do conflito trabalho-família, por estar em uma posição privilegiada para dar apoio tanto instrumental como emocional, ao demonstrar empatia pelo estresse e pressão sentidos em relação ao conflito. Recebendo esse tipo de apoio, os trabalhadores sentem-se ajudados e com a certeza de que o desempenho laboral será facilitado (Mesmer-Magnus et al., 2010; Michel et al., 2011; Rathi \& Barath, 2012). No estudo de Silveira et al. (2014) com motoristas de transporte coletivo urbano, por exemplo, o fator "colegas de trabalho" foi referido como um dos principais associados à satisfação no trabalho, assim como o "gostar de dirigir" e o "trabalho em si". A compreensão do suporte do colega de trabalho como possível redutor do conflito trabalho-família constitui uma das necessidades identificadas na literatura no âmbito dessa problemática (Breaugh \& Frye, 2008; Mesmer-Magnus et al., 2010; Rathi \& Barath, 2012).

Com base na revisão da literatura sobre a relação entre o suporte social dos supervisores e colegas e o conflito trabalho-família, são apresentadas as seguintes hipóteses:

$\mathrm{H}_{5}: \mathrm{O}$ suporte social dos supervisores relaciona-se negativamente com o conflito trabalho-família.

$\mathrm{H}_{6}: \mathrm{O}$ suporte social dos colegas relaciona-se negativamente com o conflito trabalho-família.

Com base na revisão da literatura apresentada anteriormente sobre o conflito trabalho-família e sua relação com a idade dos indivíduos (Allen \& Finkelstein, 2014; Pinto, 2012), a idade dos filhos (Allen \& Finkelstein, 2014; Pinto, 2012), a carga de trabalho semanal (DiRenzo et al., 2011; Michel et al., 2011; Netemeyer et al., 1996; Zhang \& Liu, 2011) e o suporte do contexto organizacional - supervisores (Breaugh \& Frye, 2008; Grzywacz \& Marks, 2000; Mills et al., 2014; Oliveira et al., 2013) e colegas de trabalho (Breaugh \& Frye, 2008; Mesmer-Magnus et al., 2010; Michel et al., 2011; Rathi \& Barath, 2012) -, é apresentada a última hipótese do estudo: 
$\mathrm{H}_{7}$ : A idade dos participantes, a idade dos filhos dos participantes, o número de horas de trabalho semanais e o suporte social dos supervisores e dos colegas são preditores significativos do conflito trabalho-família.

\section{MÉTODO}

\section{Participantes}

Participaram do estudo, por meio do preenchimento de um questionário, 154 motoristas de transporte coletivo urbano de uma empresa portuguesa, todos do sexo masculino, uma vez que na empresa em questão, só havia homens a desempenhar essa função. Dos motoristas, 68,9\% têm idade entre 40 e 59 anos, 86,4\% são casados ou vivem em união estável e $80,5 \%$ cursaram o ensino básico. Quanto à situação profissional, $67,5 \%$ dos motoristas trabalham na organização há mais de 10 anos, e a maioria (66,9\%) trabalha até 40 horas semanais. Do ponto de vista familiar, o agregado é composto, na maioria dos casos, por $3(35,1 \%)$ ou $4(37,7 \%)$ elementos. Os que têm filhos representam $89,6 \%$ dos motoristas, com a predominância de terem $1(34,4 \%)$ ou 2 filhos (43,5\%).

\section{Instrumentos}

A primeira parte do questionário era constituída por questões sociodemográficas de caráter familiar e profissional. São elas: idade, estado civil, escolaridade, antiguidade na organização, horas de trabalho, quantidade de pessoas na família, número de filhos e idade deles. De seguida encontravam-se quatro escalas: Conflito Trabalho-Família (CTF), Satisfação com o Trabalho (ST), Suporte Social de Supervisores (SSS) e Suporte Social de Colegas (SSC). Em todos os casos, os itens são respondidos numa escala likert de cinco pontos $(1=$ discordo totalmente a 5 = concordo totalmente), sendo que quanto mais elevada a pontuação obtida, maior a percepção da dimensão avaliada.

O Conflito Trabalho-Família (CTF) foi avaliado por meio da versão portuguesa da escala (Netemeyer et al., 1996), anteriormente usada no estudo de Pinto (2012), também com motoristas profissionais portugueses, onde exibiu boa consistência interna (alfa de Cronbach de 0,87). Essa medida baseia-se na perspectiva de tempo e tensão proposta por Greenhaus e Beutell (1985). A escala CTF é constituída por cinco itens, sendo um deles "É difícil cumprir as minhas responsabilidades familiares devido ao tempo que o meu trabalho exige". Em nosso estudo, a escala apresentou também boa consistência interna, apresentando valor de alfa de Cronbach de 0,88 .

Para avaliar a percepção da satisfação com o trabalho, recorreu-se à versão traduzida e validada para a população portuguesa por Chambel e Marques-Pinto (2008) da escala Job Satisfaction (Brayfield \& Rothe, 1951), no formato abreviado, com cinco itens (p. ex., "Sinto-me bastante satisfeito com a minha vida profissional"). No estudo de validação foi obtido um alfa de Cronbach $\alpha$ de 0,84 , enquanto em nosso estudo este situou-se em 0,79 .

Quanto às escalas restantes - Suporte Social de Supervisores (SSS) e Suporte Social de Colegas (SSC) -, dado que não existia uma medida validada para a população portuguesa que medisse o suporte social dos supervisores e dos colegas especificamente na temática conflito trabalho-família, optou-se por desenvolver uma medida a partir da escala Coworker Informal Work Accomodations to Family (subescala Help Behavior), de Mesmer-Magnus et al. (2010). No âmbito dessa medida, o suporte social é entendido como uma rede de trabalho social de comunicação de que fazem parte pessoas que se preocupam com a qualidade de vida dos outros e em quem os indivíduos podem confiar (Edwards \& Peccei, 2010). Uma vez obtida a autorização junto dos autores da escala original, procedeu-se à tradução de quatro de seus itens, trabalho efetuado com o apoio de investigadores experientes na área da psicologia do trabalho e das organizações e também a partir do contributo de duas entrevistas feitas previamente com dois motoristas (contrastantes em termos de estado civil - solteiro/ casado - e de presença de filhos - com e sem filhos) e uma entrevista com o respectivo supervisor direto.

A realização dessas entrevistas visou a uma primeira aproximação à temática em estudo naquele contexto organizacional, explorando, sobretudo, a articulação entre o trabalho e a vida fora dele, bem como o modo como a organização tendia a gerir essa articulação, formal ou informalmente. Essa opção foi tomada dada a escassez da literatura na interface trabalho - família no grupo ocupacional dos motoristas e em termos do suporte social, sobretudo por parte dos colegas, em associação com essa temática. Do ponto de vista do desenvolvimento do instrumento, tais entrevistas permitiram melhor ajustamento da linguagem à população em 
estudo. Assim, a SSC é composta por quatro itens, sendo um deles "Quando surge alguma urgência pessoal/ familiar, posso contar sempre com meus colegas”. A escala de SSS foi constituída por isomorfismo a partir da escala anterior, tendo também quatro itens (p. ex., "Meu supervisor reage bem quando chego atrasado, ou não compareço, por questões relacionadas a eventos/emergências familiares"). As propriedades psicométricas dessas escalas são apresentadas na seção Resultados.

\section{Procedimentos}

Todos os motoristas que trabalhavam em tempo integral na empresa no momento da coleta de dados (abril de 2013) foram contatados por telefone pela investigadora responsável pela coleta e convidados a participar do estudo. Do total de cerca de 170 motoristas trabalhando na empresa foram contatados 154, e todos aceitaram participar da investigação (os restantes encontravam-se de férias, de licença médica ou trabalhando em regime de tempo parcial). O questionário foi entregue em papel, no próprio local de trabalho, e seu preenchimento foi realizado em pequenos grupos de acordo com a disponibilidade dos participantes. Também era entregue, junto ao questionário, uma carta onde era explicado o âmbito do estudo, o caráter voluntário da participação e a garantia de anonimato e de confidencialidade no tratamento dos dados, sendo estas informações reforçadas oralmente pela investigadora presente na coleta de dados. Uma vez preenchidos, os questionários eram depositados pelos motoristas em uma caixa disponibilizada para tal.

As análises estatísticas foram feitas com o auxílio do Software Statistical Package for the Social Sciences - IBM SPSS, 20 -, e os dados obtidos são apresentados por estatística descritiva (média e desvio padrão).

Em função do cumprimento ou não dos pressupostos para utilização de testes paramétricos (Field, 2005), recorreu-se ao coeficiente de correlação de Pearson $(r)$ ou ao coeficiente de correlação de Spearman $(r)$ na análise das correlações, e ao teste $t$ de Student ou ao teste de Mann-Whitney $(U)$ na análise de diferenças entre grupos. No modelo de Regressão Múltipla foi usado o método stepwise, com as variáveis a cumprirem os pressupostos exigidos. No caso das escalas de SSC e SSS, os itens foram sujeitos à análise fatorial exploratória (método varimax) e à análise da confiabilidade (alfa de Cronbach) devido ao fato de sua operacionalização ter sido desenvolvida no âmbito do presente estudo. Em todas as análises estatísticas foi considerado o nível de significância $p<0,05$.

\section{RESULTADOS}

Antes de se apresentar os resultados quantitativos relativos às hipóteses formuladas, apresentam-se os resultados obtidos na análise fatorial exploratória com os itens das escalas de SSC e SSS, dado que tais medidas foram utilizadas pela primeira vez.

A análise fatorial exploratória dos eixos principais com rotação Varimax apontou para a existência de dois fatores, sendo o primeiro fator 35\% da variância total, e o segundo, 33\%. A análise do conteúdo dos itens por fator indicou que o primeiro agrupava os itens correspondentes ao suporte social dos supervisores e o segundo ao suporte social dos colegas, tendo-se considerado para a retenção dos itens uma carga fatorial superior a 0,5 (Pestana \& Gageiro, 2005). A análise de confiabilidade (consistência interna) indicou um alfa de Cronbach de 0,85 para a escala de SSS e de 0,81 para a escala de SSC, valores que indicam boa confiabilidade de ambas as medidas.

$\mathrm{Na}$ Tabela 1 são apresentadas as estatísticas descritivas (média e desvio padrão) das dimensões avaliadas: conflito trabalho-família, satisfação com o trabalho, suporte social dos supervisores e suporte social dos colegas. A sua consulta nos indica que, em média, os participantes deste estudo apresentam valores reduzidos de percepção de CTF. Em contraste, verifica-se que os valores médios obtidos nas dimensões ST, SSS e SSC encontram-se consideravelmente acima de média da escala utilizada, apontando, assim, níveis elevados de satisfação com o trabalho e de percepção de suporte dos supervisores e dos colegas. 
TABELA 1. Estatísticas descritivas das variáveis em estudo, matriz de correlações entre as variáveis e alfas de Cronbach em cada escala

\begin{tabular}{|c|c|c|c|c|c|c|}
\hline Variáveis & $M$ & $D P$ & 1 & 2 & 3 & 4 \\
\hline Conflito Trabalho-Família (CTF) & 2,6 & 1,0 & $(0,88)$ & & & \\
\hline Satisfação com o Trabalho (ST) & 3,9 & 0,62 & $-0,30^{* *}$ & $(0,79)$ & & \\
\hline Suporte Social dos Supervisores (SSS) & 3,6 & 1,1 & $-0,31^{\star *}$ & $0,31^{\star *}$ & $(0,85)$ & \\
\hline Suporte Social dos Colegas (SSC) & 4 & 0,84 & $-0,10$ & $0,24^{\star *}$ & $0,32^{\star \star}$ & $(0,81)$ \\
\hline
\end{tabular}

Nota. * $p<0,05 ;{ }^{* *} p<0,01$.

Também na Tabela 1, são apresentadas as correlações entre as várias dimensões avaliadas. Por meio de sua consulta, verifica-se que o CTF está negativamente correlacionado ao SSS $(r=-0,31 ; p<0,01)$, resultado que suporta a hipótese 5. Contrariamente ao formulado, não foi, no entanto, observada correlação entre o SSC e o CTF, resultado que conduz à rejeição da hipótese 6. Em relação à associação entre a ST e o CTF, observou-se relação negativa e estatisticamente significativa $(r=-0,30 ; p<0,01)$, resultado que permite suportar a hipótese 4 .

Em relação à associação entre a idade dos participantes e o CTF, o coeficiente de correlação de Spearman indicou que esta era negativa e estatisticamente significativa $\left(r_{\mathrm{s}}=-0,33 ; p<0,01\right)$, resultado que permite aceitar a hipótese 1.

A comparação entre a idade dos filhos dos participantes e o CFT indicou que os motoristas que têm filhos de até 15 anos (Ordem Média = 79,05) relatam maior CTF do que os motoristas que têm filhos de mais de 15 anos (Ordem Média $=54,99)$, diferença estatisticamente significativa $(U=1456,50 ; p<0,01)$. Assim, o resultado obtido suporta a hipótese 2 .

A comparação ao nível da duração da jornada de trabalho indicou que os motoristas que trabalhavam mais de 40 horas semanais referem maior CTF (Ordem Média = 98,2) do que os que trabalham menos de 40 horas semanais $($ Ordem Média $=67,29)$, diferença estatisticamente significativa $(U=1575 ; p<0,01)$, suportando, assim, a hipótese 3.

Por fim, foi testada a hipótese 7, que indicava que a idade dos participantes, a idade dos filhos dos participantes, o número de horas de trabalho semanais, o suporte dos supervisores e o suporte dos colegas constituíam preditores significativos do CTF. Dada a ausência de correlação entre o suporte social dos colegas e o CTF (Tabela 1), essa dimensão não entrou no modelo.

O resultado do modelo de regressão linear múltipla aplicado explica $30 \%$ da variância do $\mathrm{CTF},(F[3,133]$ $=18,74 ; p=0,001$ ), sendo o suporte dos supervisores o preditor com maior capacidade explicativa do CTF. Além do suporte dos supervisores, a idade dos filhos e o número de horas trabalhadas semanalmente, como pode ser observado na Tabela 2, também constituem fatores preditivos. No geral, tais resultados suportam parcialmente a hipótese 7.

TABELA 2. Resultado da análise de regressão múltipla para a dimensão conflito trabalho-família

\begin{tabular}{|c|c|c|c|c|}
\hline Preditores & $R^{2}\left(R^{2}\right.$ aj) & $F(3,133)$ & $\beta$ & $\mathbf{t}$ \\
\hline Horas trabalhadas semanalmente $\left(^{*}\right)$ & & & 0,28 & $3,84^{* * *}$ \\
\hline Idade dos Filhos $\left({ }^{\star \star}\right)$ & $0,30(0,28)$ & $18,74^{\star * *}$ & $-0,27$ & $-3,72^{\star \star *}$ \\
\hline Suporte Social dos Supervisores & & & $-0,35$ & $-4,75^{\star \star \star}$ \\
\hline
\end{tabular}

Nota. ${ }^{*} p<0,05 ;{ }^{* *} p<0,01 ;{ }^{* *} p<0,001 .\left({ }^{*}\right)$ até $40 \mathrm{~h}$ semanais ou mais de $40 \mathrm{~h}$ semanais (codificadas respetivamente como 0 e 1$)$. $\left({ }^{* *}\right)$ até 15 anos ou idade igual ou superior a 15 anos (codificadas respetivamente como 0 e 1 ).

\section{DISCUSSÃO}

Um dos propósitos principais deste estudo consistiu em analisar a percepção de conflito trabalho-família junto a um grupo de motoristas de passageiros em uma empresa municipal. De modo geral, os resultados obtidos indicam que esses profissionais, em média, apresentam valores relativamente reduzidos de CTF. Em comparação a um estudo recentemente realizado, também com um grupo de motoristas profissionais portugueses do sexo masculino (Pinto, 2012), os valores médios encontrados em nosso estudo são substancialmente mais baixos. As diferenças observadas poderão ser explicadas, ao menos em parte, pelas características de trabalho dos motoristas, em um e outro caso.

No estudo de Pinto (2012), os motoristas pertenciam a uma empresa privada e podiam ser motoristas de longa distância ou que faziam entregas. Enquanto os primeiros passavam longos períodos fora de casa, os 
segundos, embora tivessem horário de trabalho fixo, tinham jornada diária bastante longa, entrando cedo e saindo muito tarde da empresa, com implicações evidentes no tempo disponível para a dedicação à família.

Contrastando com a situação descrita anteriormente, no caso do presente estudo os motoristas pertencem a uma empresa municipal de transportes públicos, voltam para casa todos os dias, folgam duas vezes na semana e têm horários definidos com alguma antecedência, o que lhes permite, apesar de tudo, certa capacidade de organização de sua vida fora do trabalho. Acreditamos que o conjunto dos resultados referidos reforça a importância das características do trabalho na compreensão do CTF (p. ex., Chambel \& Ribeiro, 2014; Michel et al., 2011), em especial do ponto de vista dos horários de trabalho.

O tempo de trabalho é considerado um elemento-chave das condições de trabalho, dado o seu papel estruturante na vida fora da organização (Silva, 2011) e, por conseguinte, na vida familiar e social. Por outro lado, a importância de práticas flexíveis (p. ex., possibilidade de realização de trocas de horário) na adaptação aos horários de trabalho, em especial naqueles irregulares e/ou por turnos (como é o caso frequente dos horários dos motoristas), tem sido igualmente assinalada (p. ex., Prata \& Silva, 2013).

Em nosso estudo, o CTF correlacionou-se negativamente ao suporte dos supervisores, resultado consistente com a literatura (p. ex., Grzywacz \& Marks, 2000; Hill, 2005) e que reforça o papel da organização (nesse caso, o dos supervisores) na gestão da interface entre as vidas profissional e pessoal tal como preconizado, por exemplo, por Silva, Prata e Ferreira (2014).

Contrariamente ao esperado com base na literatura consultada (p. ex., Breaugh \& Frye 2008; MesmerMagnus et al., 2010), neste estudo não se obteve uma associação entre o suporte social dos colegas e o CTF. Não obstante esse resultado e considerando os dados obtidos nas entrevistas prévias à aplicação do questionário nessa organização, parece existir a possibilidade de os colegas poderem se ajudar mutuamente, designadamente por meio das trocas, embora estas tenham de ser sempre aprovadas pela supervisão. Assim, ainda que o suporte dos colegas possa ser importante, para que a redução do conflito trabalho-família seja obtida por meio das trocas, sempre é necessária a autorização por parte dos supervisores, que assumem um papel determinante na gestão cotidiana, resultado consistente com a importância assinalada por Mills et al. (2014). Por outro lado, a profissão de motorista é solitária. Contrariamente a um cenário de organização de trabalho em equipe, em que há a partilha do mesmo espaço e tempo de trabalho e onde os colegas podem solicitar ajuda com maior frequência, no caso do motorista, as trocas tendem a ser mais pontuais.

Em nosso estudo, o CTF relacionou-se negativamente com a satisfação no trabalho, resultado consistente com a literatura consultada (p. ex., Netemeyer et al., 1996; Oliveira et al., 2013), sugerindo que a obtenção de um bom equilíbrio entre os universos familiar e profissional pode ajudar no desenvolvimento de atitudes mais favoráveis face ao trabalho.

Em relação à influência de fatores sociodemográficos, familiares e profissionais, observou-se diferenças em relação à idade dos filhos e ao número de horas de trabalho semanais, resultados que são consistentes com a literatura (p. ex., Allen \& Finkelstein, 2014; DiRenzo et al., 2011; Netemeyer et al., 1996; Pinto, 2012). Indivíduos com filhos mais novos, com idade inferior a 15 anos, e que trabalham mais de 40 horas semanais são os que evidenciam maior CTF. Ao confirmar esses resultados foi possível perceber que o (maior) número de horas trabalhadas semanalmente, a (menor) idade dos filhos e o (maior) suporte por parte dos supervisores constituem os fatores que predizem o CTF neste estudo.

Acreditamos que isso possa ser explicado pelo fato de os motoristas que sentem maior conflito serem os que estão iniciando uma família e os que têm filhos menores, como observado no estudo de Allen e Finkelstein (2014) e, nesse contexto, também poderão ser aqueles que estão mais sujeitos a pressões econômicas, as quais poderão levá-los a aceitar realizar mais horas de trabalho. Por outro lado, quanto mais novos são os filhos, maior é seu grau de dependência, o que, naturalmente, influencia o modo como o tempo pode ser gerido fora do contexto de trabalho. Dito por outros termos, é esperado que, quando os filhos são menores, a flexibilidade no uso do tempo fora do contexto laboral esteja mais condicionada e regulada pelas rotinas dos próprios filhos e da vida familiar. Nesse sentido, é esperado também que a flexibilidade permitida pela organização possa ser ainda mais importante na gestão do CTF nessas circunstâncias. Por outro lado, dado que "os filhos não param de crescer enquanto os pais trabalham", acreditamos que os resultados obtidos apontam também para a importância das organizações terem em conta critérios familiares (nesse caso, a idade dos filhos) na definição das políticas relativas às escalas de horário de trabalho, de modo a maximizar o tempo livre comum entre pais e filhos. Por exemplo, se a organização privilegiar o critério antiguidade na empresa na atribuição das folgas 
nos domingos, isso poderá ser penalizador para os funcionários mais novos, sendo que são estes os que têm maior probabilidade de ter filhos em idade escolar e, portanto, com a maior parte do tempo livre coincidindo no fim de semana.

O fato deste estudo ter se baseado em apenas uma organização constitui, naturalmente, uma de suas principais limitações, dificultando a generalização dos resultados obtidos. Assim, considera-se importante que se realizem mais estudos dessa natureza, concebendo uma população mista, incorporando mais do que uma organização, onde se possa aprofundar os contributos do suporte social no local de trabalho, dos supervisores e dos colegas na diminuição do conflito trabalho-família.

Como visto anteriormente, a interação trabalho-família tornou-se uma temática que originou um conjunto de estudos empíricos em diferentes contextos e culturas. Esses estudos salientam, em geral, que as dificuldades sentidas na articulação entre papéis profissionais e familiares são não só frequentes, como também estão associados a mal-estar tanto profissional quanto familiar.

Contudo, ao caracterizar, neste estudo, os conflitos de papéis vividos por motoristas profissionais do sexo masculino, evidenciaram-se não só os antecedentes no nível profissional da ocorrência desse conflito (p. ex., número de horas semanais trabalhadas), como também aspectos que permitem minimizar a percepção de conflito sentido (p. ex., suporte social dos supervisores). Num e noutro caso, os dados apontam para o fato de as organizações poderem desempenhar um papel ativo na gestão dessa interface. Como sublinham Oliveira et al. (2013),

O entendimento da dinâmica dos conflitos entre as vidas pessoal e familiar pode auxiliar as organizações no desenho de políticas e no fomento de práticas voltadas ao equilíbrio entre esses dois universos, permitindo maior eficiência na aplicação de recursos e na criação de um ambiente organizacional mais estável e produtivo (p. 420).

Esperamos, assim, que este estudo possa alertar os gestores de recursos humanos para possibilidades de atuação no nível da conciliação entre duas das mais importantes esferas da vida do homem: o trabalho e a família.

\section{REFERÊNCIAS}

Allen, T. D. (2001). Family-supportive work environments: The role of organizational perceptions. Journal of Vocational Behavior, 58(3), 414-435. doi: 10.1006/jvbe.2000.1774

Allen, T. D., \& Finkelstein, L. M. (2014). Work-family conflict among members of full-time dual-earner couples: An examination of family life stage, gender, and age. Journal of Occupational Health Psychology, 19(3), 376-384. doi: 10.1037/a0036941

Akintayo, D. I. (2010). Work-family role conflict and organizational commitment among industrial workers in Nigeria. Journal of Psychology and Couseling, 2(1), 1-8.

Battiston, M. C., Cruz, R. M., \& Hoffmann, M. H. (2006). Condições de trabalho e saúde de motoristas de transporte coletivo urbano. Estudos de Psicologia, 11(3), 333-343. doi: 10.1590/S1413-294X2006000300011

Bianchi, S., \& Milkie, M. (2010). Work and family research in the first decade of the 21st century. Journal of Marriage and Family, 72(3), 705-725. doi:10.1111/j.1741-3737.2010.00726.x

Brandão, A. (2011). Práticas amigas da família: Contributos para a compreensão da sua adesão e eficácia (Dissertação de mestrado não publicada). Universidade do Minho, Braga, Portugal.

Brayfield, A. H., \& Rother, F. (1951). An index of job satisfaction. Journal of Applied Psychology, 35(5), 307-311. doi: 10.1037/ h0055617

Breaugh, J., \& Frye, K. (2008). Work-family conflict: The importance of family-friendly employment practices and family-supportive supervisors. Journal of Business and Psychology, 22(4), 345-353. doi: 10.1007/s10869-008-9081-1

Chambel, M. J., \& Marques-Pinto, A. (2008). Consequences of work and family facilitation in employees' satisfaction and engagement (Working Paper). Faculdade de Psicologia: Universidade de Lisboa.

Chambel, M. J., \& Ribeiro, M. T. R. (2014). Introdução. In M. J. Chambel \& M. T. R. Ribeiro (Coords.), A relação entre o trabalho e a família (pp. 6-10). Lisboa: RH Editora.

Coltrane, S., Miller, E., DeHaan, T., \& Stewart, L. (2013). Fathers and the flexibility stigma. Journal of Social Issues 69(2), 279302. doi: $10.1111 /$ josi. 12015 
De Vitta, A., De Conti, M. H. S., Trize, D. M., Quintino, N. M., Palma, R., \& Simeão, S. F. A. P. (2013). Sintomas musculoesqueléticos em motoristas de ônibus: Prevalência e fatores associados. Fisioterapia em Movimento Curitiba, 26(4), 863-871.

DiRenzo, M., Greenhaus, J., \& Weer, C. (2011). Job level, demands, and resources as antecedents of work-family conflict. Journal of Vocational Behavior, 78(2), 305-314. doi: 10.1016/j.jvb.2010.10.002

Edwards, J. R., \& Rothbard, N. P. (2000). Mechanisms linking work and family: Clarifying the relationship between work and family constructs. The Academy of Management Review, 25(1), 178-199. doi: 10.5465/AMR.2000.2791609

Edwards, M. R., \& Peccei, R. (2010). Perceived organizational support, organizational identification, and employee outcomes. Journal of Personnel Psychology, 9(1). 17-26. doi: 10.1027/1866-5888/a000007

Field, A. (2005). Discovering statistics using SPSS (2 ed.). Londres: Sage.

Guerreiro, M. D., Lourenço, V., \& Pereira, I. (2006). Boas práticas de conciliação entre vida profissional e vida familiar: Manual para as empresas. Lisboa: Comissão para a Igualdade no Trabalho e no Emprego.

Greenhaus, J. H., \& Beutell, N. J. (1985). Sources of conflict between work and family roles. Academy of Management Review, 10(1), 76-88. doi:10.5465/AMR.1985.4277352

Goldani, A. M. (2002). Família, gênero e políticas: Famílias brasileiras nos anos 90 e seus desafios como fator de proteção. Revista Brasileira de Estudos de População, 19(1), 29-48.

Grzywacz, J. G., \& Marks, N. F. (2000). Reconceptualizing the work-family interface: An ecological perspective on the correlates of positive and negative spillover between work and family. Journal of Occupational Health Psychology, 5(1), 111 - 126. doi: |0.1037//I076-8998.5.1.11।

Hill, J. (2005). Work-family facilitation and conflict, working fathers and mothers, work-family stressors and support. Journal of Family Issues, 26(6), 793-819. doi: 10.1177/0192513X05277542

Jacobs, J. A., \& Gerson, K. (2004). The time divide: Work, family and gender inequality. Cambridge: Harvard University Press.

Khan, N. (2014). Family to work conflict among working mothers in UAE. European Scientific Journal, 10(20), 205-216.

McManus, K., Korabik, K., Rosin, H. M., \& Kelloway, E. K. (2002). Employed mothers and the work-family interface: Does family structure matter? Human Relations, 55(11), 1295-1324. doi: 10.1177/0018726702055011919

Mills, M. J., Matthews, R. A., Henning, J. B., \& Woo, V. A. (2014). Family-supportive organizations and supervisors: How do they influence employee outcomes and for whom? The International Journal of Human Resource Management, 25(12), 17631785. doi: 10.1080/09585192.2013.860387

Mesmer-Magnus, J., \& Viswesvaran, C. (2009). The role of the coworker in reducing work-family conflict: A review and directions for future research. Pratiques Psychologiques, 15(2), 213-224. doi:10.1016/j.prps.2008.09.009

Mesmer-Magnus, J. R., Murase, T. M., DeChurch, L. A., \& Jimenez, M. J. (2010). Coworker informal work accommodations to family: Scale development and validation. Educational \& Psychological Measurement, 70(3), 511-531. doi:10.1177/0013164409355687

Michel, J. S., Kotrba, L. M., Mitchelson, J. K., Clark, M. A., \& Baltes, B. B. (2011). Antecedents of work-family conflict: A metaanalytic review. Journal of Organizational Behavior, 32(5), 689-725. doi: 10.1002/job.695

Netemeyer, R., Boles, J., \& McMurrian, R. (1996). Development and validation of work-family conflict and family-work conflict scales. Journal of Applied Psychology, 81(4), 400-410.

Oliveira, L. B., Cavazotte, F. S. C. N., \& Paciello, R. R. (2013). Antecedentes e consequências dos conflitos entre trabalho e família. Revista de Administração Contemporânea, 17(4), 418-437. doi: 10.1590/S1415-65552013000400003

Pestana, M. H., \& Gageiro, L. N. (2005). Análise de dados para ciências sociais: A complementariedade do SPSS. Lisboa: Edições Sílabo.

Pinto, C. (2012). Interface trabalho-família em motoristas profissionais (Dissertação de mestrado). Recuperado de http:// repositorium.sdum.uminho.pt/bitstream/1822/21249/1/Carlos\%20Alberto\%20Azevedo\%20Pinto.pdf

Prata, J., \& Silva, I. S. (2013). Efeitos do trabalho em turnos na saúde e em dimensões do contexto social e organizacional: Um estudo na indústria eletrónica. Revista Psicologia: Organizações e Trabalho, 13(2), 141-154.

Rathi, N., \& Barath, M. (2012). Work-family conflict and job and family satisfaction: Moderating effect of social support among police personnel. Equality, Diversity and Inclusion: An International Journal, 32(4), 438 - 454. doi: 10.1108/EDI-10-20120092

Silva, I. S. (2011). O factor tempo nas condições de trabalho: O caso do trabalho por turnos. In A. D. Gomes (Coord.), Psicologia das organizações, do trabalho e dos recursos humanos (pp. 365-426). Coimbra: Imprensa da Universidade de Coimbra. 
Silva, I. S., Prata, J., \& Ferreira, A. I. (2014). Horários de trabalho por turnos: Da avaliação dos efeitos às possibilidades de intervenção. International Journal on Working Conditions, 7, 68-83.

Silveira, L. S., Abreu, L. C., \& Santos, E. M. (2014). Análise da situação de trabalho de motoristas em uma empresa de ônibus urbano da cidade de Natal-RN. Psicologia Ciência e Profissão, 34(1), 158-179. doi: 10.1590/S1414-98932014000100012

Sultana, A. (2013). Constraints faced by working and non-working women in their families. Australian Journal of Basic and Applied Sciences, 7(6), 719-722.

Sutton, K. L., \& Noe, R. A. (2005). Family-friendly programs and work-life integration: More myth than magic? In E. E. Kossek \& S. L. Lambert (Eds.), Work and life integration: Organizational, cultural and individual perspectives (pp. 151-169). London: Lawrence Erlbaum Associates.

Thompson, C., Beauvais, L., \& Lyness, K. (1999). When work-family benefits are not enough: The influence of work-family culture on benefit utilization, organizational attachment, and work-family conflict. Journal of Vocational Behavior, 54, 392-415. doi: 10.1006/jvbe.1998.1681

Tüchsen, F., Hannerz, H., Roepstorff, C., \& Krause, N. (2006). Stroke among male professional drivers in Denmark. Occupational and Environmental Medicine, 63, 456-460. doi: 10.1136/oem.2005.025718

Vandello, J. (2013). When equal isn't really equal: The masculine dilemma of seeking work flexibility. Journal of Social Issues, 69(2), 303-321. doi: 10.1111/josi.12016

Williams, J. (2010). Reshaping the work-family debate: Why men and class matter. Cambridge: Harvard University Press.

Zhang, J., \& Liu, Y. (2011). Antecedents of work-family conflict: Review and prospect. International journal of business and management, 6(1), 89-103. doi: 10.5539/ijbm.v6n1p89 